\title{
Makara Journal of Science
}

Volume 25

Issue 3 September

Article 7

9-30-2021

\section{Analysis on the Crystal Structure of the Piezoelectric Nanocrystal Ceramic of Pr-doped Bi1/2Na1/2TiO3 using Molten-Salt Synthesis}

\author{
Syahfandi Ahda \\ Center for Science, Technology of Advanced Materials, National Nuclear Energy Agency, Serpong 15314, \\ Indonesia, ahda@batan.go.id \\ Vita Ambarwati \\ Departement of Chemistry, Universitas Negeri Malang, Malang 65145, Indonesia \\ Mardiyanto Mardiyanto \\ Center for Science, Technology of Advanced Materials, National Nuclear Energy Agency, Serpong 15314, \\ Indonesia \\ Engkir Sukirman \\ Center for Science, Technology of Advanced Materials, National Nuclear Energy Agency, Serpong 15314, \\ Indonesia \\ Bambang Sugeng \\ Center for Science, Technology of Advanced Materials, National Nuclear Energy Agency, Serpong 15314, \\ Indonesia \\ Follow this and additional works at: https://scholarhub.ui.ac.id/science \\ Part of the Physical Sciences and Mathematics Commons
}

\section{Recommended Citation}

Ahda, Syahfandi; Ambarwati, Vita; Mardiyanto, Mardiyanto; Sukirman, Engkir; and Sugeng, Bambang (2021) "Analysis on the Crystal Structure of the Piezoelectric Nanocrystal Ceramic of Pr-doped Bi1/2Na1/ 2TiO3 using Molten-Salt Synthesis," Makara Journal of Science: Vol. 25 : Iss. 3 , Article 7.

DOI: $10.7454 / \mathrm{mss} . v 25 i 3.1246$

Available at: https://scholarhub.ui.ac.id/science/vol25/iss3/7

This Article is brought to you for free and open access by the Universitas Indonesia at UI Scholars Hub. It has been accepted for inclusion in Makara Journal of Science by an authorized editor of UI Scholars Hub. 


\title{
Analysis on the Crystal Structure of the Piezoelectric Nanocrystal Ceramic of Pr-doped $\mathrm{Bi}_{1 / 2} \mathrm{Na}_{1 / 2} \mathrm{TiO}_{3}$ using Molten-Salt Synthesis
}

\author{
Syahfandi Ahda ${ }^{1 *}$, Vita Ambarwati ${ }^{2}$, Mardiyanto $^{1}$, Engkir Sukirman $^{1}$, and Bambang Sugeng ${ }^{1}$ \\ 1. Center for Science, Technology of Advanced Materials, National Nuclear Energy Agency, Serpong 15314, Indonesia \\ 2. Departement of Chemistry, Universitas Negeri Malang, Malang 65145, Indonesia \\ *E-mail: ahda@batan.go.id
}

Received June 7, 2021 | Accepted August 5, 2021

\begin{abstract}
One of the future technologies in nuclear reactors is the ability of piezoelectric materials to monitor reactor cores as sensors. Particularly, $\mathrm{Pb}$-free piezoelectric materials, such as $\mathrm{Bi}_{1 / 2} \mathrm{Na}_{1 / 2} \mathrm{TiO}_{3}$, have been examined to improve the ability of their piezoelectric properties. In this study, we attempted to add $\operatorname{Pr}_{6} \mathrm{O}_{11}$ dopant material with mole ratios of 0 , 0.3 , 0.5 , and $0.7 \mathrm{~mol} \%$. The synthesis process used in this study is the molten-salt synthesis method with a $\mathrm{NaCl}$ and $\mathrm{KCl}$ salt mole ratio of 1:1. The crystal structure analysis using the refinement process of the Rietveld method of the HighScore software was performed. Accordingly, a rhombohedral crystal structure system with lattice parameters of 3.8809(2), 3.8831(2), 3.8834(7), and 3.8816(2) angstroms and variations in the content of $\operatorname{Pr}_{6} \mathrm{O}_{11}$ was obtained. The optimal lattice parameter was discovered with the addition of $0.5 \mathrm{~mol} \%$ of $\operatorname{Pr}_{6} \mathrm{O}_{11}$. The morphology of the synthesis product is still unclear for each addition of dopant material due to the large number of granular agglomerations.
\end{abstract}

Keywords: Goldschmidt's tolerance, molten-salt method, piezoelectric materials

\section{Introduction}

The unique properties of piezoelectric ceramic materials are useful for current and future applications. This material principle can convert mechanical stress or deformation into an electrical output, and if electricity is applied to the material, it will result in shape changes or deformations. Thus, it is widely applied in electronic and mechanical devices [1]. One of them that gives great hope is to be used as a transducer or sensor placed in the core of a nuclear reactor. Studies have been performed to monitor and improve the safety of modern reactors, as has been done by one of the research groups of D. A. Parks et al. [2]. Another application is energy harvesting to generate electricity, such as in the case of the wheels of a car pressing piezoelectric devices placed along highways, which generates mass power. This method has been applied on the highways of developed countries, such as Israel, Japan and Germany, to light up villages. Its development is also being intensively carried out in their study [3].

At present, the piezoelectric material of $\mathrm{PbZr}_{\mathrm{x}} \mathrm{Ti}_{(1-\mathrm{x})} \mathrm{O}_{3}$ (PZT), which has high performance, has been widely applied, but it contains $\mathrm{Pb}$, which is not environmentally friendly. Therefore, lead-free piezoelectric materials that are superior to replace $\mathrm{PZT}$, such as $\mathrm{BaTiO}_{3}$ (BT) and $\mathrm{Bi}_{1 / 2} \mathrm{Na}_{1 / 2} \mathrm{TiO}_{3}(\mathrm{BNT})$, have been formulated. This
BNT has received more attention than BT due to its high Curie temperature and piezoelectric constant. BNT is a ferroelectric material that was first discovered by Smolenskii et al. [4]. It is considered an excellent leadfree material and has a rhombohedral perovskite structure at room temperature $[5,6]$. Therefore, the study on environmentally friendly BNT materials needs to be intensively developed with the addition of a dopant. Such an addition will change the structure itself, thus affecting the amount of piezoelectric constant or the performance of the material.

The synthesis process technology for piezoelectric materials is an important part in improving the quality of ready-to-use materials. Accordingly, several researchers have used several synthesis methods, including dry method (solid-state reaction) [7], and wet methods, such as hydrothermal [8], sol-gel [9], and molten-salt reaction [10]. Each synthesis process tends to obtain products with different characteristics. The BNT piezoelectric material is an interesting thing to be developed with the addition of the $\operatorname{Pr}_{6} \mathrm{O}_{11}$ dopant material (labeled as BNT-Pr hereinafter), especially in the synthesis process.

Several researchers have conducted research on BNT-Pr with various synthesis methods, including $\mathrm{H}$. Sun et al. [7] and A. Paul Blesing et al. [11], using the solid-state 
reaction synthesis method and Khairunnisa Abdul Razak et al. [12] using a gentle combustion technique. In this study, we applied the molten-salt method for the continuation of a new series of BNT-Pr synthesis processes. However, molten-salt synthesis is a relatively simple process, has low energy consumption, and can easily control the shape and size of crystals [13]. This study focuses on a BNT product synthesized by the molten-salt method and then analyzes the changes in the crystal structure with the addition of $\operatorname{Pr}_{6} \mathrm{O}_{11}$ dopant variations using Rietveld analysis.

The $\operatorname{Pr}_{6} \mathrm{O}_{11}$ dopant material with mole ratios of $0,0.3$, 0.5 , and $0.7 \mathrm{~mol} \%$ for each BNT sample have been applied in the molten-salt synthesis process with a sintering temperature of $875{ }^{\circ} \mathrm{C}$. The HighScore Plus (PANalytical) software has also been used to support the analysis of crystal structures.

\section{Experimental Method}

The BNT-Pr synthesis procedure using the molten-salt method begins by weighing the base materials, such as $\mathrm{Bi}_{2} \mathrm{O}_{3}$ (ABCR; 99.99\% purity), $\mathrm{Na}_{2} \mathrm{CO}_{3}$ (Merck; 99.9\% purity), $\quad \mathrm{TiO}_{2}$ (Merck; 99.9\% purity), and $\mathrm{Pr}_{6} \mathrm{O}_{11}$ (ABCR; 99.9\% purity), through stoichiometry and then mixing and crushing them for 4 hours. With the balance in stoichiometry, the equation for the reaction that occurs in the BNT synthesis process is as follows:

$\mathrm{Bi}_{2} \mathrm{O}_{3}+\mathrm{Na}_{2} \mathrm{CO}_{3}+4 \mathrm{TiO}_{2} \rightarrow 4 \mathrm{Bi}_{0.5} \mathrm{Na}_{0.5} \mathrm{TiO}_{3}+\mathrm{CO}_{2}$

The Pr-doped BNT powder was signed according to the formula of $\left(\mathrm{Bi}_{1 / 2} \mathrm{Na}_{1 / 2}\right)_{(1-\mathrm{x})} \mathrm{Pr}_{\mathrm{x}} \mathrm{TiO}_{3}$ (where $0.3 \%<x<$ $0.7 \%$ ) was synthesized using the molten-salt method [7].

The salt used was a mixture of eutectic $\mathrm{NaCl}$ and $\mathrm{KCl}$ with a mole ratio of 1:1. A mixture of salt and a base material with a weight ratio of 1:1 was crushed for 2 hours to get smaller and more homogeneous particles $[10,14]$. The synthesis process was continued by sintering at $875{ }^{\circ} \mathrm{C}$ for 4 hours. The sintering temperature was below the melting point of the base material, while the mixture of $\mathrm{NaCl}$ and $\mathrm{KCl}$ salts were melted. The reaction mechanism among the base materials took place through a diffusion process in liquid salts and formed new compounds [11]. Then, the salt content in the sample as a synthesized product was removed by washing it with boiling aquabides $\left(100{ }^{\circ} \mathrm{C}\right)$ and filtering it repeatedly. The absence of salt was tested with drops of colorless $\mathrm{AgNO}_{3}$ solution into the liquid after filtering the sample. Finally, the BNT products obtained were dried at $100{ }^{\circ} \mathrm{C}$. The laboratory steps in the synthesis process using the molten salt method are presented in Figure 1.

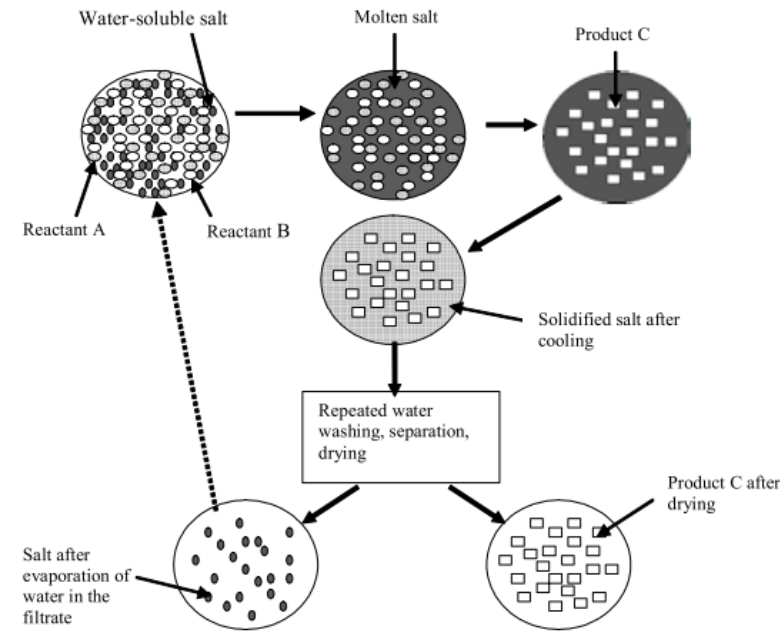

Figure 1. Schema of the Synthesis Procedure using the Molten-Salt Method [15]

The BNT samples with the addition of $\operatorname{Pr}_{6} \mathrm{O}_{11}$ dopants were characterized using X-ray diffraction (XRD) and scanning electron microscopy (SEM). The results of the XRD pattern were analyzed using the Rietveld method with the HighScore Plus (PANalytical) software to determine the crystal structure system.

\section{Results and Discussion}

A perovskite crystal structure system, as shown in the piezoelectric material, is defined as an $\mathrm{ABO}_{3}$ compound with a network of $\mathrm{B}-\mathrm{O}$ octahedral sharing angles that surround the large cation site $A$ (ionic radii of $r_{A}>r_{B}$ ). To predict the stability of the perovskite structure based on the $\mathrm{ABO}_{3}$ (non-experimental) chemical formula, the Goldschmidt's tolerance factor $(t)$ involving the ionic radius of each ion (A, B, and $\mathrm{O}$ ) was used [16]:

$\mathrm{t}=\left(\mathrm{r}_{\mathrm{A}}+\mathrm{r}_{\mathrm{O}}\right) / 2^{1 / 2}\left(\mathrm{r}_{\mathrm{B}}+\mathrm{r}_{\mathrm{O}}\right)$

As mentioned above, the BNT-Pr formula is $\left(\mathrm{Bi}_{1 / 2} \mathrm{Na}_{1 / 2}\right)_{(1-\mathrm{x})} \mathrm{Pr}_{\mathrm{x}} \mathrm{TiO}_{3}$. It has a perovskite structure system, such that site $A$ is occupied by $\left(\mathrm{Bi}_{1 / 2} \mathrm{Na}_{1 / 2}\right)_{(1-}$ $\left.{ }_{x}\right) \operatorname{Pr}_{x}$ and site $\mathrm{B}$ is occupied by Ti. In this modified BNT, the $\mathrm{Pr}^{3+}$-doped ion radius is smaller than the average Asite ion radius of the undoped BNT. In other words, the occupation of site $\mathrm{A}$ by $\operatorname{Pr}^{3+}$ ions causes lattice shrinkage due to the formation of cation vacancies at site $\mathrm{A}$ and with $\mathrm{Pr}^{3+}$ ion size smaller than $\mathrm{Bi}^{3+}$ and $\mathrm{Na}^{+}$ sizes (ionic radii: $0.139,0.140$, and $0.126 \mathrm{~nm}$ for $\mathrm{Bi}^{3+}$, $\mathrm{Na}^{+}$[17], and $\mathrm{Pr}^{3+}$, respectively). The $t$ value of BNT-Pr was obtained in the range of $0.98745-0.98786$, as shown in Figure 2.

The reduction of the tolerance factor is still assumed to be in a stable region because it is mathematically related to a small A-site substitution. In general, the stability of perovskite structures is estimated to occur in the range 


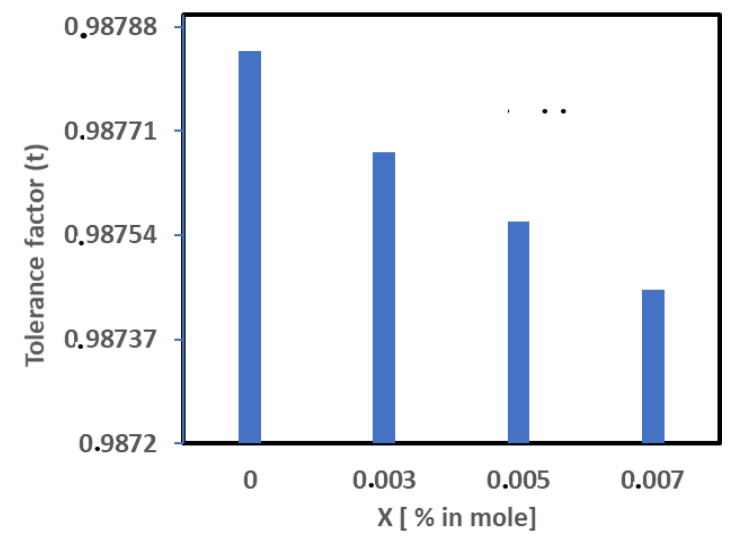

Figure 2. Goldschmidt's Tolerance Factor for the Addition of Dopant Pr6O11 Represented by $X$ in the Percentage of Moles

of $0.880<t<1.090$ [18]. Therefore, the value of $t$ also gives an indication of how far the atom can move from its ideal packing position and is still "tolerated" in the perovskite structure. However, a high symmetry can generally occur at $t$ values closer to 1 (as a cubic structure, the piezoelectricity is very weak). The addition of a dopant material reflects structure modifications, such as rotation, distortion, and octahedral tilt. Thus, changes in structural factors can affect the piezoelectric properties.

Crystal structure analysis. The variations in the addition of the $\operatorname{Pr}_{6} 0_{11}$ dopant into each sample were 0 , $0.3,0.5$, and $0.7 \mathrm{~mol} \%$ (BNT for no addition and BNTPr for the addition of Pr), as shown in Figure 3. A change in color was observed for each sample, as shown before and after the synthesis. The results indicate a reaction among the base materials to form new compounds. Accordingly, these new compounds were identified using the XRD profile.

Figure 4 shows the XRD pattern of the BNT synthesis product without dopants and the base material of the $\mathrm{Pr}_{6} \mathrm{O}_{11}$ dopant. The presence of the three highest peaks for $\mathrm{BNT}$ at $2 \theta$ diffraction angles, i.e., $32.57^{\circ}, 46.66^{\circ}$, and $58.12^{\circ}$, can be identified as the $\mathrm{Bi}_{1 / 2} \mathrm{Na}_{1 / 2} \mathrm{TiO}_{3}$ (BNT) pattern. This condition was also investigated by S. Dargham with synthesis using the sol-gel method [9]. Meanwhile, $\operatorname{Pr}_{6} \mathrm{O}_{11}$ peaks were not found in the BNT pattern itself. The formation of a single-phase BNT with a perovskite structure occurred during the synthesis process. The identification of this BNT pattern corresponds to the file on the Joint Committee on Powder Diffraction Standard No. 36-340 with a perovskite rhombohedral crystal system. In other words, the XRD profile indicates that a single phase of BNT was obtained due to the absence of other foreign peaks in the synthesis product. Therefore, the diffusion and reaction processes among the base materials in the BNT synthesis with the molten-salt method were successfully conducted to form new compounds.

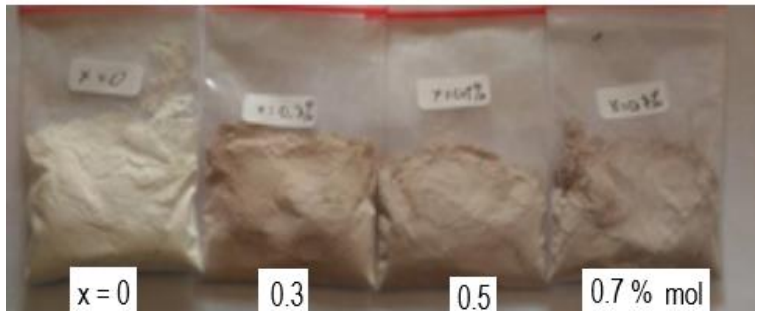

(a)

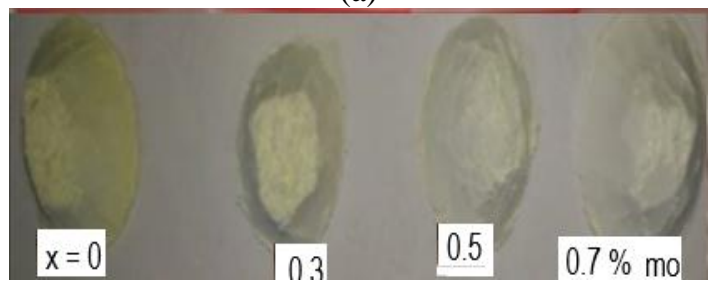

(b)

Figure 3. Samples with Variations in the Addition of $\operatorname{Pr}_{6} \mathrm{O}_{11}$ Dopants $(0,0.3,0.5$, and $0.7 \mathrm{~mol} \%)$ before the Sintering Process (a) and after the Sintering Process (b). A Color Change Occurred Very Clearly after Sintering

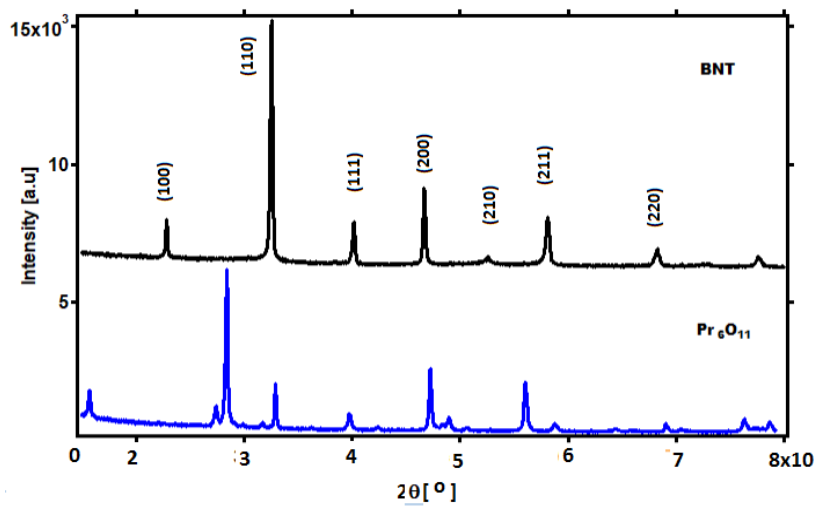

Figure 4. XRD Profile for the Synthesis Product without Dopants (BNT) and the Dopant Base Material of $\operatorname{Pr}_{6} \mathrm{O}_{11}$

However, in the XRD profile, particularly the rhombohedral structure, it is rather difficult to distinguish because of the overlapping peaks, such that the lattice parameters are close to cubic. The lattice angle parameters are also very close for certain piezoelectric materials. Due to the small degree of distortion in the rhombohedral structure for BNT or BNT-Pr crystals, the peak lines of the diffraction plane were indexed based on the pseudocubic crystal system. $[19,20]$. The ionic $\mathrm{Bi}$ radius is close to $\mathrm{Na}$ in its cell unit, which causes a slight lattice distortion. Doping with Pr with an ionic radius of $1.26 \AA$ in BNT causes local lattice contractions and then distorts the lattice. However, the very close ionic radius causes unclear lattice distortion level changes. Moreover, the $\mathrm{Ti}$ ion radius is $0.605 \AA$ [20], which is quite far from that of the Prion. Therefore, the occupation of the Pr ion in the A-site position will be very possible. 
As already mentioned, in the absence of $\operatorname{Pr}_{6} \mathrm{O}_{11}$ peaks, the occurrence of praseodymium ion substitution in the perovskite lattice is possible. Moreover, the close ionic radii of the three elements prepares the substitution of $\mathrm{Pr}^{3+}$ ions for $\mathrm{Bi}^{3+}$ ions or $\mathrm{Na}^{+}$ions into the perovskite lattice, because Pr ions with a charge of $2+$ or $3+$ can replace the A site in the BNT perovskite structure with an $\mathrm{ABO}_{3}$ group.

The diffraction pattern of BNT and BNT-Pr syntheses at various additions of the $\operatorname{Pr}_{6} \mathrm{O}_{11}$ dopant content is presented in Figure 5 (black dots represent the data). Intensity data as a function of diffraction angle were refined using the HighScore Plus software by entering the parameters of the starting point shift, background, space group, and unit cell. The success of a refinement process can be seen from the statistical errors indicated in the values of the profile factor $\left(R_{p}\right)$ and weighted profile factor $\left(\mathrm{R}_{\mathrm{wp}}\right)$. According to Kniess and Tamer, the success of a refinement process occurs when the value of $\mathrm{R}_{\mathrm{p}}$ and $\mathrm{R}_{\mathrm{wp}}$ is below $10 \%$ [21-23]. In this case, for samples added with $\operatorname{Pr}_{6} \mathrm{O}_{11}(0,0.3,0.5$, and 0.7 mol\%), the values of $\mathrm{R}_{\mathrm{p}}$ and $\mathrm{R}_{\mathrm{wp}}$ were obtained, as shown in Table 1.

The results of the sample analysis with the values of $R_{p}$ and $R_{\mathrm{wp}}$ below $10 \%$ indicate a refinement process with good agreement, as shown in Figure 5. The results of the refinement process as a diffraction pattern performed on the BNT and BNT-Pr samples can be displayed with close calculation data (red) and experimental data (black), where the difference (green) is very low.

The rhombohedral perovskite crystal system on BNT with the addition of $\operatorname{Pr}_{6} \mathrm{O}_{11}$ dopant has also been demonstrated as has been investigated by Dargham et al. for addition of other dopant to BNT [9, 22, 24-26]. In the HighScore Plus software, there is no direct rhombohedral crystal system available. Therefore, to perform Rietveld analysis, we used a hexagonal system as an input parameter, with space group R3c, and then converted it to a rhombohedral crystal system with Inorganic Crystal Structure Database number 98-0280983.

In this study, the lattice shift and its doping effect on $\mathrm{R} 3 \mathrm{c}$ (space group) were refined on the hexagonal axis and then linked to pseudocubic/rhombohedral cells. The best agreement between the observed (obs) and calculated (cal) interplanar distances at the Bragg angle was found for a rhombohedral crystal structure (space group R3c) with a hexagonal axis.

Hexagonal lattice parameters as the output of the refinement process are indicated by $a_{h}$ and $c_{h}$. The transformation from the hexagonal axis to rhombohedral axis was performed using Equations 3-4, as described by Moreau, J. M et al. [27] and Paul Blessington Selvadurai et al. [11]. First, the conversion to a primitive rhombohedral unit cell was conducted by calculating the $a_{\mathrm{pr}}$ and $\alpha_{\mathrm{pr}}$ parameters through the following equation:

$a_{p r}=\sqrt{\frac{a_{h}^{2}}{3}+\frac{c_{h}^{2}}{9}}$ and $\sin \frac{\alpha_{p r}}{2}=\left(2 \sqrt{\frac{1}{3}+\frac{c_{h}^{2} / a_{h}^{2}}{9}}\right)^{-1}$

Table 1. Output Data from the Refinement Process with a Statistical Error of the Profile Factor $\left(R_{p}\right)$ and Weight Profile Factor $\left(\mathbf{R}_{\mathrm{wp}}\right)$

\begin{tabular}{lll}
\hline Sample & $\mathbf{R}_{\mathbf{p}}$ & $\mathbf{R}_{\mathbf{w p}}$ \\
\hline $0 \% \operatorname{Pr}_{6} \mathrm{O}_{11}$ & 4.6291 & 6.0538 \\
$0.3 \% \operatorname{Pr}_{6} \mathrm{O}_{11}$ & 4.8945 & 6.4188 \\
$0.5 \% \operatorname{Pr}_{6} \mathrm{O}_{11}$ & 4.8709 & 6.3020 \\
$0.7 \% \operatorname{Pr}_{6} \mathrm{O}_{11}$ & 4.5148 & 6.0858 \\
\hline
\end{tabular}

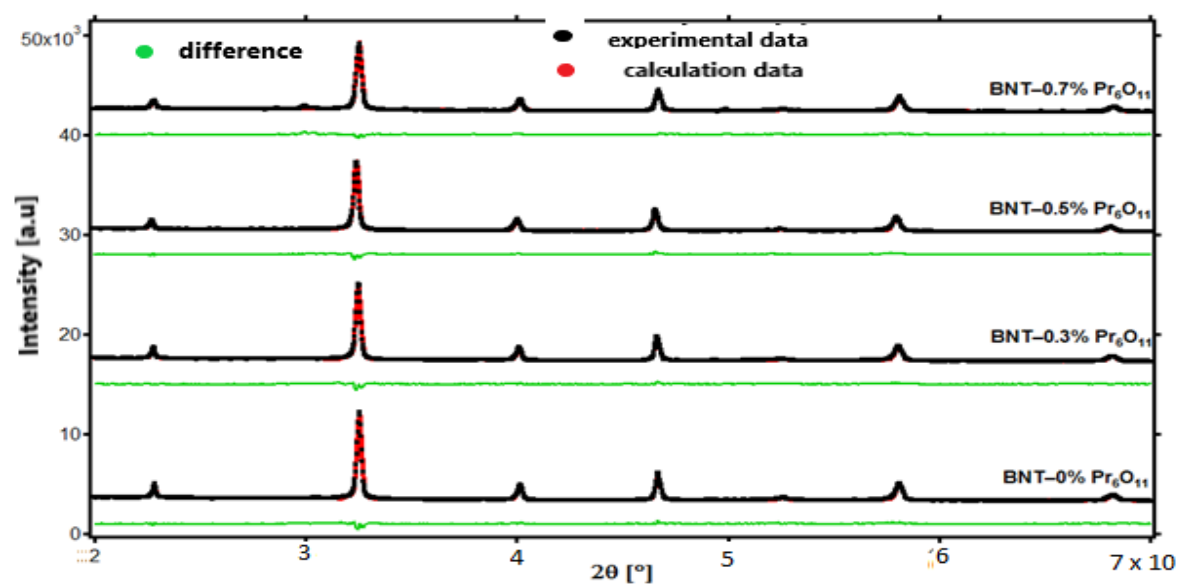

Figure 5. BNT Diffraction Patterns with Variations in the Addition of the $\operatorname{Pr}_{6} \mathrm{O}_{11}$ Dopants $(0,0.1,0.3$, and 0.7 mol\%) 
Table 2. Calculation Results of the Lattice Parameters for BNT with the Addition of $\operatorname{Pr}_{6} \mathrm{O}_{11}$ Dopants at 0, 0.3, 0.5, and 0.7 mol\%

\begin{tabular}{ccccccccc}
\hline \multirow{2}{*}{ Sample } & \multicolumn{3}{c}{ Hexagonal } & \multicolumn{3}{c}{ Rhombohedral } \\
& $\mathbf{a h}[\dot{\mathbf{A}}]$ & $\mathbf{c h}_{\mathbf{h}}[\dot{\mathbf{A}}]$ & $\left.\boldsymbol{\alpha}_{\mathbf{h}}=\boldsymbol{\beta}_{\mathbf{h}}{ }^{\circ}\right]$ & $\gamma_{\mathbf{h}}\left[{ }^{\circ}\right]$ & volume $\left[\dot{\mathbf{A}}^{3}\right]$ & arh $[\dot{\mathbf{A}}]$ & $\boldsymbol{\alpha}_{\mathbf{r h}}\left[{ }^{\circ}\right]$ & volume $\left[\dot{\mathbf{A}}^{3}\right]$ \\
\hline $0 \% \operatorname{Pr}_{6} \mathrm{O}_{11}$ & $5.4836(3)$ & 13.466 & 90 & 120 & 350.595 & $3.8809(2)$ & 89.905 & $58.451(3)$ \\
$0.3 \% \operatorname{Pr}_{6} \mathrm{O}_{11}$ & $5.4891(3)$ & 13.460 & 90 & 120 & 351.206 & $3.8831(2)$ & 89.960 & $58.547(3)$ \\
$0.5 \% \operatorname{Pr}_{6} \mathrm{O}_{11}$ & $5.490(1)$ & 13.459 & 90 & 120 & 351.308 & $3.8834(7)$ & 89.970 & $58.565(10)$ \\
$0.7 \% \operatorname{Pr}_{6} \mathrm{O}_{11}$ & $5.481(3)$ & 13.484 & 90 & 120 & 350.807 & $3.8816(2)$ & 89.835 & $58.483(3)$ \\
\hline
\end{tabular}

After the calculation of the primitive unit cell, it is then converted into unit cell parameters $\left(a_{\mathrm{fc}}\right.$ and $\alpha_{\mathrm{fc}}$ ) for rhombohedral center-face cells $(Z=8)$, which are determined by the following equations.

$a_{f c}=\frac{1}{2} a_{p r} \sqrt{3-2 \cos \alpha_{p r}}$ and $\cos \alpha_{f c}=\frac{2 \cos \alpha_{p r}-1}{3-2 \cos \alpha_{p r}}(4)$

The length of the rhombohedral (pseudocubic) unit cell $a_{\mathrm{rh}}$ was obtained from $\mathrm{a}_{\mathrm{fc}} / 2$ and $\alpha_{\mathrm{rh}}=\alpha \mathrm{fc}$. The calculated results are listed in Table 2. Meanwhile, the change in lattice parameters for BNT with the addition of $\operatorname{Pr}_{6} \mathrm{O}_{11}$ dopants was calculated, as shown in Table 2.

The effect of the addition of dopants can be seen from the results of the refinement process in Figure 6, which shows the clear change in the intensity between the data (black dots) and their calculation (red lines) at diffraction angles with ranges of $32^{\circ}-33^{\circ}$ and $46.2^{\circ}$ $47^{\circ}$. Systematically, the reflection plane peak shift to the left from the BNT peak $(x=0 \mathrm{~mol} \%)$ with the addition of $x=0.3 \mathrm{~mol} \%$ and $0.5 \mathrm{~mol} \%$ of $\operatorname{Pr}_{6} \mathrm{O}_{11}$ dopants resulted in a large lattice plane distance $(d)$ or increased lattice parameters (Table 2). Conversely, with the addition of $x=0.7 \mathrm{~mol} \%$, the peak shifts back to the right. Thus, the plane distance $(d)$ becomes smaller or the lattice parameter decreases (Table 2). The optimal lattice parameter for the rhombohedral structure is $a=$ $3.8834 \AA$ and the alpha angle $=89.970^{\circ}$ obtained in the addition of dopant $x=0.5 \mathrm{~mol} \%$, while it is almost close to the cubic structure. The diffraction pattern shift is presented in Figure 5.

The high/low of a peak that affects the broad/narrow of the peak can be represented as a full width at half maximum (FWHM). Accordingly, the crystallite size of each sample can be interpreted. The Williamson-Hall (W-H) method as a function of FWHM and peak position $2 \theta$ can be applied in determining the size of crystallites and strain [28].

Using this approach, the W-H plot can be formulated as a straight-line function using the equation $\beta \cos \theta=\mathrm{k} \lambda / \mathrm{d}$ $+4 \varepsilon(\sin \theta)$. The results of the refinement process in this study are illustrated in Figures 6, where $d$ is the size

Makara J. Sci.

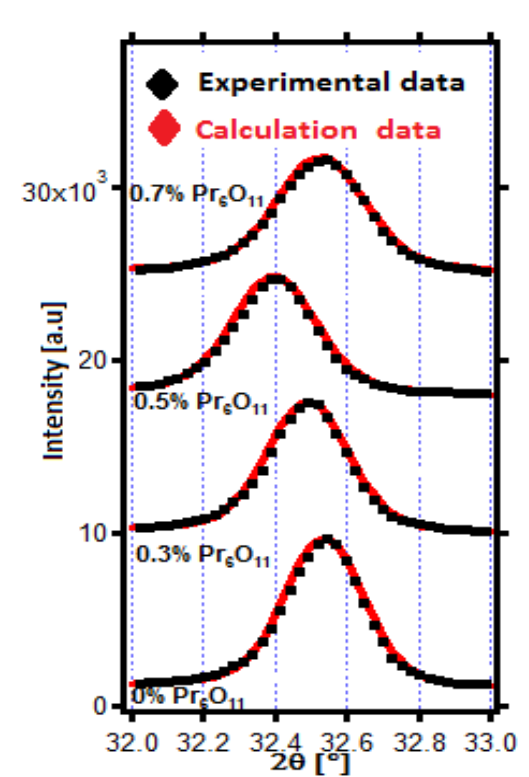

(a)

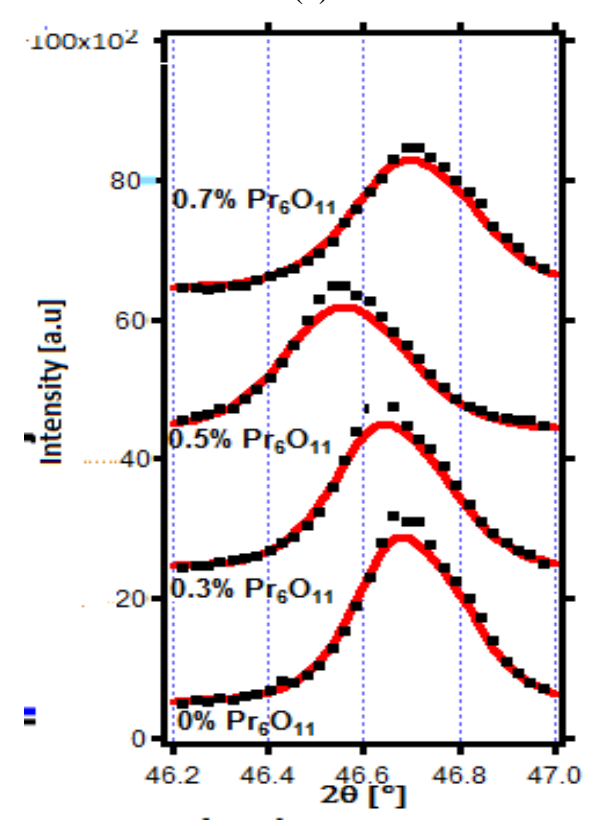

(b)

Figure 6. Peak Shift Pattern of the BNT Diffraction Due to the Addition of Pr6O11 Dopants (a) at an Angle of $2 \theta 32^{\circ}-33^{\circ}$ and (b) $46.2^{\circ}-47^{\circ}$

September $2021 \mid$ Vol. 25 No. 3 
of the crystallite, $\varepsilon$ is the elastic strain, $\beta$ is the FWHM, and $K$ is the Scherrer constant (or an arbitrary value that falls in the range of $0.87-1.0$ ). We usually assume $k=1$. The determination of the FWHM on the XRD intensity profile was first corrected with standard silicon samples, as was performed by Engkir S [29]. Thus, the size of the crystallite was obtained through an extrapolation of the above equation.

Figure 7 shows a linear statistical regression with equations that can be interpreted into the W-H equation. A statistical coefficient $(R)$ above $90 \%$ indicates a very good agreement with the regression quality, as it is also supported by the results of good refinement. Intercepts to the Y-axis can be calculated to obtain the crystallite size as a function of adding a dopant material. Finally, the size of the crystallites obtained for $x=0.3,0.5$, and $0.7 \mathrm{~mol} \%$ were $61.62,51.69$, and $42.79 \mathrm{~nm}$, respectively.

BNT morphological analysis with the addition of Pr6 $_{6} \mathrm{O}_{11}$ dopants. BNT and BNT-Pr images were taken using the JEOL JSM-6510LA SEM tool to examine the grain morphology formed from the synthesis results with a magnification of 10,000 times, as shown in Figure 8. The shape and size of the grain BNT and BNT-Pr showed an unclear and formed agglomeration. Visually, the addition of a dopant material forms small grain sizes, so it fits with the XRD data analysis ranging from 40 to $65 \mathrm{~nm}$.

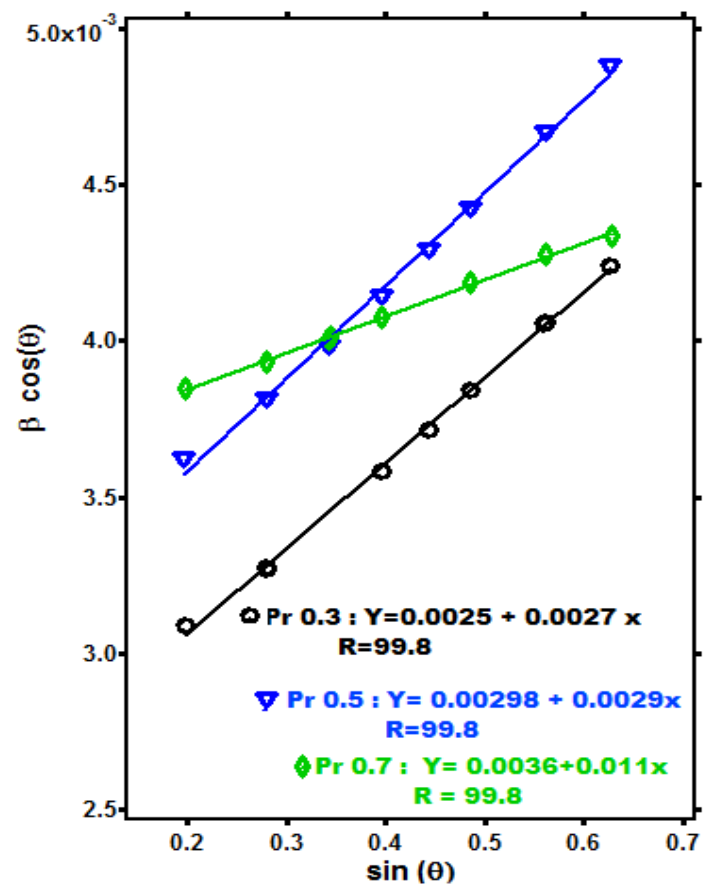

Figure 7. Williamson-Hall (W-H) Plot of the Refinement Process Results for the BNT Phase with the Addition of $\operatorname{Pr}_{6} \mathrm{O}_{11}$ Dopants $(x=0.3,0.5$, and 0.7 mol\%, Respectively), where $\beta \cos (\theta)=Y$ and $\sin$ $(\boldsymbol{\theta}) \mathbf{X}$

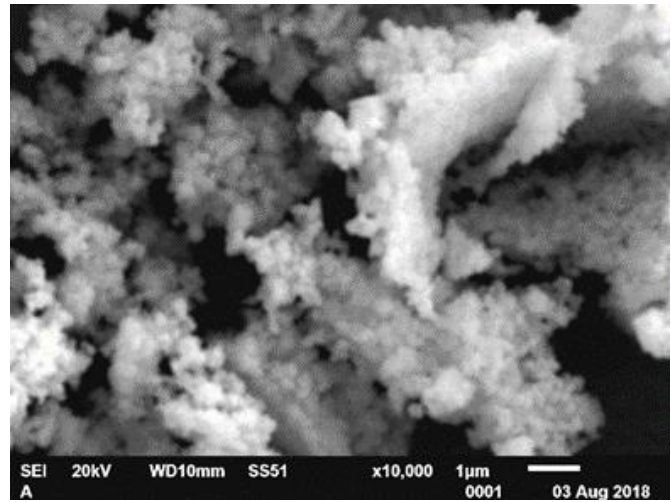

(a)

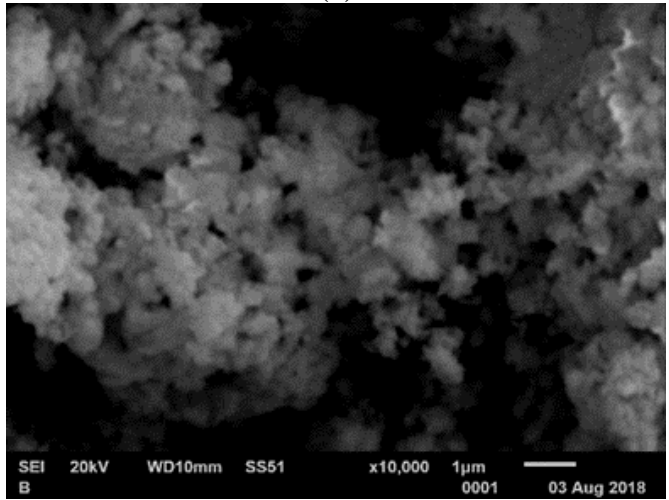

(b)

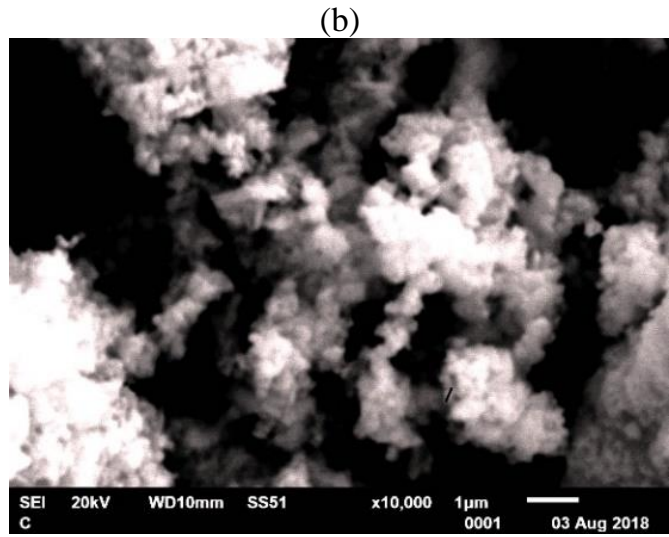

(c)

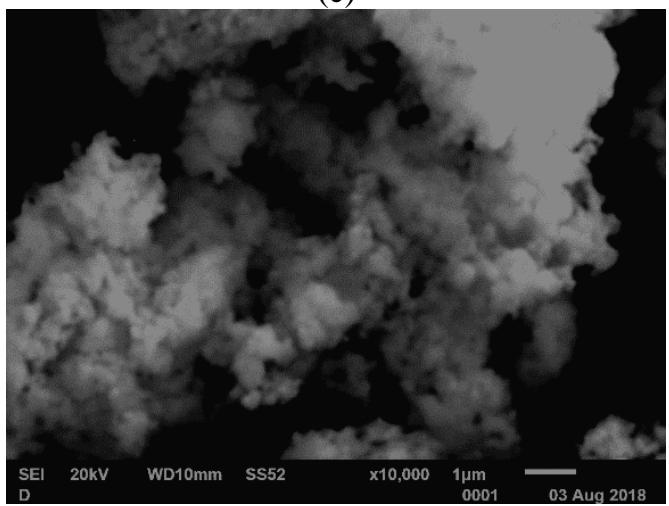

(d)

Figure 8. Morphology of BNT-Pr Crystals from the Reaction Results in the Molten-Salt Method: (a) $0 \%$, (b) $0.3 \%$, (c) $0.5 \%$, and (d) $0.7 \% \mathrm{~mol} \operatorname{Pr}_{6} \mathrm{O}_{11}$ 
Table 3. Percentage of Atoms in the BNT and BNT-Pr Product Compounds with the Addition of Pr6O11 Dopant Materials

\begin{tabular}{cccccc}
\hline Sample & $\mathbf{B i}$ & $\mathbf{N a}$ & $\mathbf{~ \% ~ A t o m ~}$ & $\mathbf{T r}$ & $\mathbf{O}$ \\
\cline { 2 - 6 } & 14.70 & 11.34 & 27.75 & 0.00 & 46.21 \\
$0 \% \operatorname{Pr}_{6} \mathrm{O}_{11}$ & 16.69 & 10.99 & 32.22 & 0.20 & 39.91 \\
$0.3 \% \operatorname{Pr}_{6} \mathrm{O}_{11}$ & 14.30 & 9.94 & 27.58 & 0.32 & 47.86 \\
$0.5 \% \operatorname{Pr}_{6} \mathrm{O}_{11}$ & 15.27 & 7.37 & 30.97 & 1.69 & 44.70 \\
$0.7 \% \operatorname{Pr}_{6} \mathrm{O}_{11}$ & & & &
\end{tabular}

In this study, a semi-quantitative analysis with energydispersive spectroscopy (EDS) was successfully performed to identify the presence of basic materials of $\mathrm{Bi}, \mathrm{Na}, \mathrm{Ti}$ atoms, and Pr dopant atoms in certain scan areas. (In addition, it is important to identify other contaminants.) Moreover, EDS can qualitatively show the tendency of the content of the constituent atoms in the compound, as shown in Table 3.

In the EDS analysis of BNT and BNT-Pr compounds, the synthesis products showed an increase in the percentage of $\mathrm{Pr}$ atoms and a decrease in $\mathrm{Na}$ atoms, as shown in Table 3. However, the percentage of $\mathrm{Bi}$ atoms did not show a tendency to decrease, and Ti atoms were not yet stable because the EDS tool used for identification is semi-quantitative.

\section{Conclusion}

The Goldschmidt's tolerance model indicates that the addition of a $\operatorname{Pr}_{6} \mathrm{O}_{11}$ variation in the $\mathrm{Bi}_{1 / 2} \mathrm{Na}_{1 / 2} \mathrm{TiO}_{3}$ synthesis is sufficient to obtain the characteristics of a piezoelectric material. The synthesis of $\mathrm{Bi}_{1 / 2} \mathrm{Na}_{1 / 2} \mathrm{TiO}_{3}$ and addition of $0 \%-0.7$ mol\% using the molten-salt method was successfully performed at $875{ }^{\circ} \mathrm{C}$ for 4 hours. The XRD pattern analysis results show that the compound formed is a crystal structure with a rhombohedral perovskite system. The addition of 0.3 and $0.6 \mathrm{~mol} \% \operatorname{Pr}_{6} \mathrm{O}_{11}$ dopants shows a shift in the XRD peak to the left, which consequently causes an increased distance change between the reflection planes $(d)$ and a larger lattice parameter. Meanwhile, the addition of 0.7 mol\% $\operatorname{Pr}_{6} \mathrm{O}_{11}$ dopant shifts to the right, so the lattice parameter becomes smaller. The maximum lattice parameters obtained were $a=3.8834 \AA$ and $\alpha=89.970^{\circ}$ for the addition of the dopant with $x=0.5 \mathrm{~mol} \%$. The $\mathrm{W}-\mathrm{H}$ plot identified a decrease in the crystal sizes of $61.62,51.69$, and $42.79 \mathrm{~nm}$, with the dopant material of $0.3,0.5$, and $0.7 \mathrm{~mol} \%$, respectively. The morphological differences using the SEM technique with a magnification of 10,000 for the synthesis product showed unclear images.

\section{Acknowledgements}

We are grateful to Dr. Ridwan, the director of the Center for Advanced Materials Science and Technology Research Center, and Dr. Abu Khalid, the head of the
Advanced Materials Division, who allowed to conduct this research and extended their financial support. We also acknowledge the scientific discussions and initial work of Dr. Fauziatul Fajaraoh, M.Sc. and Deswita, which have been very helpful in the laboratory work and writing of this paper.

\section{References}

[1] Pohanka, M. 2017. The piezoelectric biosensors: Principles and applications, a review. Int. J. Electrochem. Sci. 12(1): 496-506, http://dx/doi/or g/10.20964/2017.01.44.

[2] Parks, D.A., Reinhardt, B., Tittmann, B.R. 2012. Piezoelectric material for use in a nuclear reactor core. AIP Conf. Proc. 1430(31): 1633-1639, http://dx/doi/org/10.1063/1.4716409.

[3] Grzybek, D. 2013. Piezoelectric generators: Materials and structures. Pomiary Automatyka Robotyka. 10: 123-129.

[4] Agranovskaya, A., K., N.N., Smolenskii, G.A. 1961. New ferroelectrics of complex composition IV. Sov. Phys. Solid State. 2: 2651-2654.

[5] Badapanda, T., Venkatesan, S., Panigrahi, S., Kumar, P. 2013. Structure and dielectric properties of bismuth sodium titanate ceramic prepared by auto-combustion technique. Process. Appl. Ceram. 7(3): 135-141, http://dx/doi/org/10.2298/ pac1303135b.

[6] Reichmann, K., Feteira, A., Li, M. 2015. Bismuth Sodium Titanate based materials for piezoelectric actuators. Mat. Basel. 8(12): 8467-8495, http://dx/doi/org/10.3390/ma8125469.

[7] Sun, H., Peng, D., Wang, X., Tang, M., Zhang, Q., Yao, X. 2011. Strong red emission in Pr doped (Bi0.5Na0.5)TiO3 ferroelectric ceramics. J. Appl. Phys. 110(1): 3-6, http://dx/doi/org/10.1063/1.36 06425.

[8] Cao, Y., Zhu, K., Wu, Q., Gu, Q., Qiu, J. 2014. Hydrothermally synthesized barium titanate nanostructures from K 2Ti4O9 precursors: Morphology evolution and its growth mechanism. Mater. Res. Bull. 57: 162-169, http://dx/doi/org/1 0.1016/j.materresbull.2014.05.043.

[9] Dargham, S.A., et al. 2016. Lead-free Bnt Piezoelectric thin films by sol-gel method. 1(1): 4-6.

[10] Ahda, S., Mardiyanto, Mahyudin, A. 2013. Aplikasi metode molten salt untuk sintesis bahan 
piezoelektrik Bi0,5(Na0,75K0,25)0,5TiO3. J. Sci. Mater. Ina. 4(14): 284-289.

[11] Selvadurai, A.P.B., Pazhnivelu, V., Vasanth, B.K., Jagadeeshwaran, C., Murugaraj, R. 2015. Investigation of structural and optical spectroscopy of 5\% Pr doped (Bi0.5Na0.5) $\mathrm{TiO} 3$ ferroelectric ceramics: site depended study. J. Mater. Sci. Mater. Electron. 26(10): 7655-7665, http://dx/doi/org/1 0.1007/s10854-015-3405-5.

[12] Razak, K.A., Yip, C.J., Sreekantan, S. 2011. Synthesis of (Bi0.5Na0.5) TiO3 (BNT) and Pr doped BNT using the soft combustion technique and its properties. J. Alloys Compd. 509(6): 2936-2941, http://dx/doi/org/10.1016/j.jallcom.2010.11.163.

[13] Setasuwon, P., Vaneesorn, N., Kijamnajsuk, S., Thanaboonsombut, A. 2005. Nanocrystallization of $\mathrm{Bi0.5Na0.5TiO3}$ piezoelectric material. Sci. Technol. Adv. Mater. 6(3-4): 278-281, http://dx/doi/org/10.1016/j.stam.20 05.03.005.

[14] Ahda, S., Misfadhila, S., Parikin, P., Putra, T.Y.S.P. 2017. Molten salt synthesis and structural characterization of BaTiO 3 nanocrystal ceramics. IOP Conf. Ser. Mater. Sci. Eng. 176(2017): 012048 http://dx/doi/org/10.1088/1757899X/176/1/012048.

[15] Zhang, S. 2007. Low temperature synthesis of complex refractory oxide powders from molten salts. J. Pakistan Mater. Soc. 1(2): 49-53.

[16] Bartel, C.J., et al. 2019. New tolerance factor to predict the stability of perovskite oxides and halides. Sci. Adv. 5(2): 1-10, http://dx/doi/org/ 10.1126/sci adv.aav0693.

[17] Ashok, K., Sarah, P. 2018.Electrical properties of sodium and neodymium modified SrBi4Ti4O15 piezoelectric ceramics. Ferroelectrics. 524(1): 8694, http://dx/doi/org/10.1080/00150193.2018.1432 875.

[18] Lee, W.C., Huang, C.Y., Tsao, L.K., Wu, Y.C. 2009. Chemical composition and tolerance factor at the morphotropic phase boundary in $(\mathrm{Bi} 0.5 \mathrm{Na} 0.5)$ TiO3-based piezoelectric ceramics. J. Eur. Ceram. Soc. 29(8): 1443-1448, http://dx/doi/org/10.1016/ j.jeurc eramsoc.2008.08.028.

[19] Fukuchi, E., Kimura, T., Tani, T., Takeuch, T., Saito, Y. 2002. Effect of potassium concentration on the grain orientation in bismuth sodium potassium titanate. J. Am. Ceram. Soc. 85(6): 1461-1466, http://dx/doi/org/10.1111/j.11512916.2002.tb002 97.x.
[20] Pattipaka, S., Peddigari, M., Pamu, D. 2017. Structural, dielectric and AC-conductivity studies of $\mathrm{Gd}$ doped lead-free $\mathrm{Bi} 0.5 \mathrm{Na} 0.5 \mathrm{TiO} 3$ ceramics. Ferroelectrics. 518(1): 59-65, http://dx/doi/org/10.1 080/00150193.2017.1360122.

[21] Kniess, C.T., de Lima, J.C., Prates, P.B. 2012. The quantification of crystalline phases in materials: Applications of rietveld method. Sintering Methods Products. 293-315.

[22] Xu, Q., et al. 2016. Structure and electrical properties of lead-free $\mathrm{Bi} 0.5 \mathrm{Na} 0.5 \mathrm{TiO} 3$-based ceramics for energy-storage applications. RSC Adv. 6(64): 59280-59291, http://dx/doi/org/ 10.1039/C6 RA11744A.

[23] Tamer, M. 2013. Quantitative phase analysis based on rietveld structure refinement for carbonate rocks. J. Mod. Phys. 04(08): 1166-1174, http://dx/do i/org/10.4236/jmp.2013.48155.

[24] Parija, B., Badapanda, T., Sahoo, P., Kar, M., Kumar, P., Panigrahi, S. 2013. Structural and electromechanical study of $\mathrm{Bi} 0.5 \mathrm{Na} 0.5 \mathrm{TiO} 3-\mathrm{BaTiO} 3$ solid-solutions. Process. Appl. Ceram. 7(2): 73-80, http://dx/doi/org/10.2298/pac1302073p.

[25] Jiang, G. 2015. Preparation and based Lead-Free thin films by Pulsed Laser Deposition, KTH Royal Institute of Technology Information and Comunication Technology, Stochlom, Sweden. pp.1-44.

[26] Chandrasekhar, M., Kumar, P. 2015. Synthesis and characterizations of BNT-BT and BNT-BT-KNN ceramics for actuator and energy storage applications. Ceram. Int. 41(4): 5574-5580, http://dx/doi/org/10.1016/j.ceramint.2014.12.136.

[27] Moreau, J.-M., Michel, C., Gerson, R., James, W.J. 1970. Atomic displacement relationship to rhombohedral deformation in some perovskite-type compounds. Acta Crystallogr. Sect. B Struct. Crystallogr. Cryst. Chem. 26(10): 1425-1428, http://dx/doi/org/10.1107/s0567740870004272.

[28] Prabhu, Y.T., Rao, K.V., Kumar, V.S.S., Kumari, B.S. 2014. X-ray analysis by Williamson-Hall and size-strain plot methods of $\mathrm{ZnO}$ nanoparticles with fuel variation. World J. Nano Sci. Eng. 4(March): 21-28.

[29] Engkir, S., Yosef, S. 2013. X-rays diffraction study on the iron nanoparticles prepared by two Step milling method. J. Sains Mater. Ind. April 2012: 67-73. 